\title{
Conditions for the adoption of conservation agriculture in Central Morocco: an approach based on Bayesian network modelling
}

\author{
Laura Bonzanigo, ${ }^{1,2}$ Carlo Giupponi, ${ }^{1,2}$ Rachid Moussadek ${ }^{3}$ \\ 'Department of Economics, Ca' Foscari University of Venice, Cannareggio (VE), Italy; \\ ${ }^{2}$ Euro-Mediterranean Centre for Climate Change, Island of San Giorgio Maggiore, Venice, \\ Italy; ${ }^{3}$ National Institute of Agronomic Research, Rabat, Morocco
}

\begin{abstract}
Research in Central Morocco, proves that conservation agriculture increases yields, reduces labour requirements, and erosion, and improves soil fertility. However, after nearly two decades of demonstration and advocacy, adoption is still limited. This paper investigates the critical constraints and potential opportunities for the adoption of conservation agriculture for different typologies of farms. We measured the possible pathways of adoption via a Bayesian decision network (BDN). BDNs allow the inclusion of stakeholders' knowledge where data is scant, whilst at the same time they are supported by a robust mathematical background. We first developed a conceptual map of the elements affecting the decision about tillage, which we refined in a workshop with farmers and researchers from the Settat area. We then involved experts in the elicitation of conditional probabilities tables, to quantify the cascade of causal links that determine (or not) the adoption. Via BDNs, we could categorise under which specific technical and socio-economic conditions no tillage agriculture is best suited to
\end{abstract}

Correspondence: Laura Bonzanigo, Department of Economics, Ca' Foscari University of Venice, Fondamenta San Giobbe 873, 30170 Cannareggio (VE), Italy.

E-mail: l.bonzanigo@gmail.com

Key words: Adoption; Bayesian decision networks; Central Morocco; conser vation agriculture.

Acknowledgements: this research was carried out within the Europe-AID project ACLIMAS. Valentina Giannini helped in organising the first workshop and set up the MCA evaluation phase. Our warm thanks to all experts who filled in the CPT questionnaires, to the support of INRA Rabat and INRA Settat, to the INRM/CRP-DS project for the data which helped build the model, and to all the interviewed farmers.

Conference presentation: SIA XLIII Congress, Pisa, 2014.

Received for publication: 15 February 2015.

Revision received: 7 September 2015.

Accepted for publication: 10 September 2015.

(C) Copyright L. Bonzanigo et al., 2016

Licensee PAGEPress, Italy

Italian Journal of Agronomy 2016; 11:665

doi:10.4081/ija.2016.665

This article is distributed under the terms of the Creative Commons Attribution Noncommercial License (by-nc 4.0) which permits any noncommercial use, distribution, and reproduction in any medium, provided the original author(s) and source are credited. which farmers. We, by identifying the main constraints and running sensitivity analyses, were able to convey clear messages on how policy-makers may facilitate the conversion. As new evidence is collected, the BDN can be updated to obtain evidence more targeted and fine tuned to the adoption contexts.

\section{Introduction}

Many experts believe that conservation agriculture (CA) is a panacea for the problems of poor agricultural productivity and environmental degradation, particularly in semi-arid areas that are characterised by frequent droughts and dry spells (Giller et al., 2009; Kassam et al., 2014). Indeed, awareness is growing around the world of the negative effects of conventional agriculture, particularly on soil quality and high yield variability (Gonzalez-Sanchez et al., 2015). Several governments and international donors promote $\mathrm{CA}$ as a means to increase crop water use efficiency and to stabilise yields, even in a changing climate (Baudron et al., 2012). For one, the World Bank views CA as a gateway to sustainable development (Derpsch, 2003).

$\mathrm{CA}$ is a sustainable agricultural production system, which rests on three principles. These are: i) minimum or no mechanical soil disturbance; ii) permanent organic soil cover (consisting of a growing crop or a dead mulch of crop residues); and iii) diversified crop rotations (Dumanski et al., 2006; Kassam et al., 2014).

Derpsch et al. (2010) estimate that around 111 million ha may be cropped under CA, but that this is mainly under commercial farming systems in the Americas and Australia. Despite this broad introduction of CA, its impact on crop yields and its applicability in different farming contexts are highly debated (Johansen et al., 2012; Pittelkow et al., 2015). In semi-arid rainfed contexts, however, there seems to be a consensus that CA may perform better than conventional agriculture, if all three principles can be implemented (Pittelkow et al., 2015).

In Morocco, CA began to be promoted in 1990s, in response to issues of soil conservation, drought mitigation, and soil quality management. Field tests by the National Institute of Agronomic Research (INRA) and development organisations (i.e., the World Bank) have successfully demonstrated that the introduction of CA would bring more stable yields and lower production costs, reduced soil erosion, greater soil water conservation, improved soil quality, stable and higher crop yields, and lower production costs (Boughlala and Dahan, 2011; Moussadek et al., 2011; Mrabet et al., 2012). For Central Morocco, Boughala and Dahan (2011) estimate a net gain of about $60 \%$ for large farmers and $200 \%$ for small farmers. Nevertheless, these data derive largely from demonstration trials, where all necessary inputs - such as herbicides, or forage management - are optimally available and implementable. Reality may not be as favourable, as the implementation of the three principles, and especially residue retention and the appropri- 
ate rotation are often challenging, especially amongst smallholders [In this paper, we refer to small holders as farmers with less than 5 ha.] (Haggblade and Tembo, 2003).

Indeed, despite the successful demonstrations in research stations and two decades of advocacy, CA found limited adoption in Moroccan farm communities (and elsewhere in Africa; Giller et al., 2011; Acevedo et al., 2014). Despite remarkable efforts, to date, adoption in Central Morocco still lingers around 1\% (The World Bank, 2014a).

In Morocco, the main constraints to adoption of CA seem to be the unavailability of no tillage seeders, lack of knowledge, non-conducive market conditions for the optimal CA rotation (cereal-legumes, to control weeds), and residue retention (Bonzanigo, personal interviews, 2014; The World Bank, 2014a). Independently of the specific reason, the low adoption rates suggest that farmers are not yet convinced about the CA technological package.

A shift from tillage, plough-based agriculture to CA-based agriculture is not a simple matter of technical change (Kassam et al., 2014; Gonzalez-Sanchez et al., 2015). The adoption of CA requires learning new practices, introducing long-term changes in the production system, and changing machinery. Moreover, the specific climate and pedologic conditions, farm management settings, market contexts, technical conditions, and socio-economic drivers, may affect a farmers' decision to adopt CA (Wall, 2007; Lahmar, 2010). For instance, Arrue and Cantero-Martínez (2006) show that despite the fact that most studies conducted in Southern Spain suggest that yields are generally 10-15\% higher under CA, especially in dry years and in dry areas, considerations of higher yields did not determine farmers' adoption - but rather the availability of subsidies for the no tillage seeders.

Thus, the decisional drivers of a farmer need to be considered from a system perspective. For successfully promoting adoption, it is often not sufficient that demonstration trials show a potentially higher productivity and economic analysis suggest potential cost savings (as in Boughala and Dahan (2011). For policy makers, the successful promotion of CA to replace conventional tillage systems requires that farmers fully understand the large economic, social, and environmental benefits that these systems offer (Kassam et al., 2014).

Rogers (2003) identifies five characteristics that an innovation needs to satisfy for users to adopt it. These five characteristics are: i) relative advantage; ii) compatibility; iii) complexity; iv) trialability; and v) observability. Relative advantage is the degree to which an innovation is perceived to perform better than the existing system. Compatibility expresses the degree to which an innovation is compatible with the existing values and fulfils the needs of the potential adopters. Complexity refers to the degree to which an innovation is perceived difficult to understand and/or to use. Trialability is the degree to which an innovation may be experimented with on a limited basis. Finally, observability is the degree to which the results of an innovation are visible to others. Moreover, the efforts of the change agents in diffusing the innovation also play a role - but they are per se not sufficient. To date, efforts in Central Morocco have been focusing primarily on demonstrating the relative advantage of $\mathrm{CA}$ versus conventional tillage systems ( $i$, in Rogers' conditions). Local institutes first began with demonstration trials in their own experimental fields and they have recently begun to collaborate with large farmers who adopt CA on a small portion of their land. The hope is that experimenting the innovation on a limited basis (iv), which is at the same time very visible to all farmers $(v)$, may raise more interest and confidence in the CA package (iii). The limited adoption in Morocco may partly depend on the fact that, to our knowledge, a comprehensive and quantitative assessment of the conditions for adoption by the different typologies of local farms (i.e, compatibility) does not yet exist. Yet, compatibility is an essential feature of adoption. Research found that even in Europe, the frequent incompatibility with either the farm systems or the fields' physical conditions, made it difficult and socio-economically risky for farmers to move away from tillage (Lahmar, 2010). The inability to manage the poor adoption of technologies that perform well in demonstration projects often resides in the poor understanding of different farmers' contexts and constraints (Baudron et al., 2012).

Kassam (2014) highlights that too little ex ante analysis has been conducted to better understand how specific policies will work and what impact they may have on farmers. Most past research on adoption focused on ex post, rather than ex ante assessments (Knowler and Bradshaw, 2007; Baudron et al., 2012; Moussadek et al., 2014).

We seek to help bridge this gap. In this study, we propose an analytical framework for an ex ante evaluation of possible policy measures to promote CA in Central Morocco. The framework focuses on the compatibility of CA with, and partially its complexity for, the existing farming system. It first examines the baseline context to identify its performance relative to conventional agriculture, from a local perspective. Then it explores the main constraints to and advantages of adoption, and investigates their cumulative impact on adoption. It further explores how adoption rates may change, if some constraints were removed via the introduction of different policy packages.

To reach these objectives, first we identify what farmers' objective priorities for the long term's survival of their farm may be - under the assumption that these factors may influence their decision to adopt CA. Then, we test and demonstrate the practicality and value added of Bayesian decision networks (BDN) for policy evaluation, in a context of high data uncertainty. Our hope is that the tool we develop in this paper may equip policy makers in Morocco to better manage the compatibility attribute. This should help them complement their current demonstration efforts for a more successful increase of adoption rates.

\section{Materials and methods}

\section{The semi-arid region of Central Morocco}

The region of Central Morocco is the most important production area for cereals in Morocco, both in terms of share in agricultural surface and production (Mrabet et al., 2012). Our analysis includes primarily data and experts of the regions Chaouia Ouardigha and Zemmour Zaer

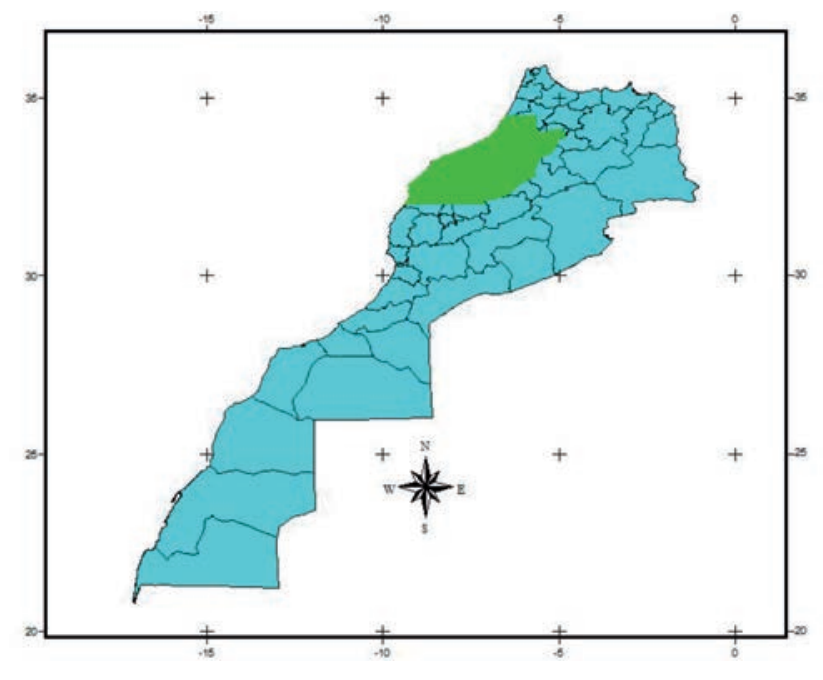

Figure 1. Morocco: the green colour is the area of interest, Central Morocco. 
(Figure 1). The climate in the region is classified as sub-humid to semiarid. Annual rainfall in this area undergoes large yearly fluctuations, with an average of around $350 \mathrm{~mm}$ (Mrabet et al., 2012). Soil types vary. About $50 \%$ of the region has deep clay soils (mainly vertisol, cambisol, and calcisol), but shallow stony, shallower soft chalky, and salty red soils are also present. The average farm size is relatively small - about 9.2 ha of cultivated land per farmer. Fifty percent of farmers are smallholders with up to 5 ha of cultivated land, $36 \%$ are medium farmers, with 5 to 20 ha, and the remaining $14 \%$ are large farmers, with more than $20 \mathrm{ha}$. Small farmers occupy $31 \%$ of the area, medium farmers $50.5 \%$, and large farmers $18.5 \%$. Crops grow under rainfed conditions in $96.5 \%$ of the cases. At present, the predominant crop rotation in the region is cereal/cereal - either durum wheat monoculture or alternated durum wheat and barley (84\%). Only $15 \%$ of farmers apply cerea/legumes or weedy fallow rotation (cereals one year, fallow the second year), and these numbers keep decreasing. According to farmers, the decrease in using this rotation is essentially due market prices, which are more stable for cereals, and the higher labour and herbicide requirements of legumes (Boughlala and Dahan, 2011). The production system is based on crop and livestock integration. The main sources of forage in the semi-arid region in Morocco are: i) cereal residues including straw and stubble (2.8 million ha); ii) weedy fallow (1.4 million ha); and iii) rangeland (6 million ha) (Watts and El Mourid, 1988). Many farmers in Morocco grow cereal in rotation with weedy fallow. Of the 7 million ha of arable land, 2 million ha are left to weedy fallow annually following a cereal crop. In a survey conducted in the semi-arid region, $25 \%$ of the arable land was weedy fallow. Farmers claim that they practice cereal/weedy fallow rotation because they cannot continuously crop cereals, and need the weeds as forage for their livestock. The increasingly common cereal-cereal rotation, driven by market prices, means that even in this case, farmers must use the residues to feed their livestock. For small farmers in particular, livestock and farming systems are highly dependent on each other. Agriculture by-products represent valuable and cheap feed sources for animal production. The strong link and integration between crop production and livestock is a widespread strategy to face the risks related to climatic variability and markets fluctuations. Despite the successful demonstrations in research stations, lack of incentives from the government and social factors seem to encourage the continued use of conventional tillage systems (Mrabet, 2008; Moussadek et al., 2011). Researchers blame the unavailability of no tillage seeder machine and lack of knowledge as two important constraints for widespread adoption of CA (The World Bank, 2014a). Farmers add both weed management issues and the incompatibility of CA with their farm management, which closely integrates livestock and farming, and is not conducive to residue retention (Bonzanigo, personal interviews, 2014). Farmers, and particularly smallholders, find challenging to leave sufficient residues on the fields rather than feed them to their animals. Farm management and the availability of inputs vary greatly according to the farm size. For small farmers, some constraints are much more severe than for large farmers. One example is the affordability of herbicides, which CA system in most cases need more than tilled systems. However, some other constraints, such as for instance the availability of labour with expertise in CA and of no tillage seeders, affect all farmers equally. Thus, we must determine what the optimum means are for achieving CA benefits for different farmers' typologies (Kassam et al., 2014).

\section{Methodological framework}

The overall methodological framework has six phases, all built upon processes eliciting judgments from experts and integrating them with

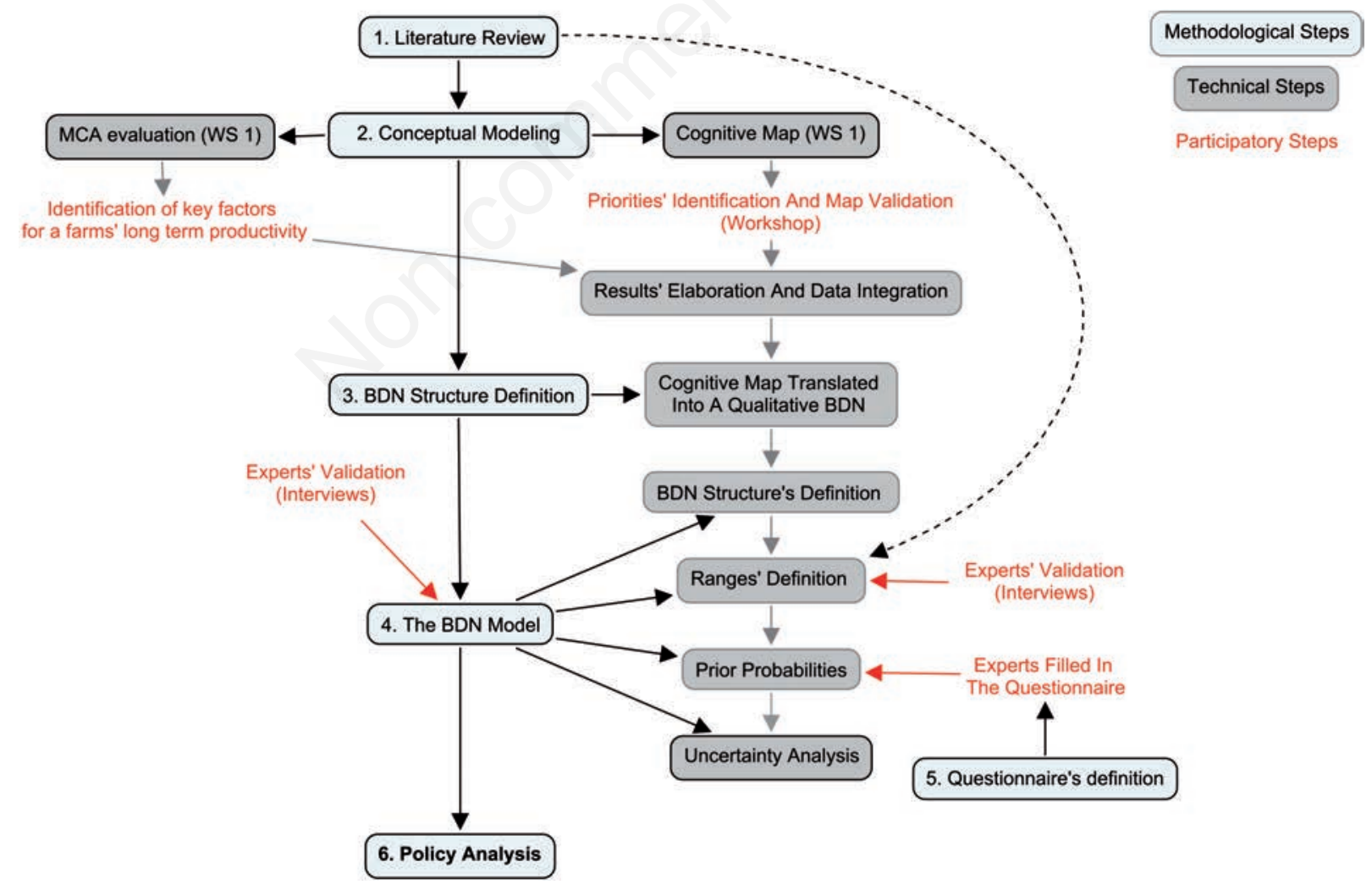

Figure 2. Coupling multi criteria analysis (MCA) and conceptual modelling (Step 2), and Bayesian network development (BDN) (Steps 3-5) for the exploration of policy packages (Step 6) (adapted from Carpani and Giupponi, 2010). 
quantitative analysis (Figure 2). These are: i) a literature review and preliminary interviews to frame the problem and set up the analysis (Step 1); ii) conceptual modelling developed at the first workshop, WS1 (Step 2), including a multi criteria analysis (MCA) evaluation to identify the factors that according to local stakeholders most influence a farm's productivity in the long term (Step 2a), and a conceptual modelling of the factors, which may influence a farmer's decision to switch to CA - and their qualitative causal relationship (Step 2b); iii) these steps ( $a$ and b) informed Step 3; iv and v) the fully functional, probabilistic tree structure of the BDN model (Steps 3 to 5); vi) policy or scenario analysis, where we simulate different changes into the system (Step 6).

\section{What affects a farms' productivity in the long term? (Step 2a)}

Often, CA supporters argue that it solves problems of erosion and water conservation, and it guarantees more stable yields. However, there is lack of consensus on what specifically drives a farmer's decision to adopt CA (Knowler and Bradshaw, 2007). In this phase, we ranked local farmers' and researchers' perceptions on what may affect a farm's productivity in the long term and how they expect these elements to perform under conventional and CA systems.

In the MCA elicitation, we asked participants to evaluate the contribution of 11 indicators to the performance of conventional agriculture and CA, via a likert scale from $0=$ very negatively to $5=$ very positively. These indicators, which we validated with local experts before the workshop, were: i) soil erosion [natural resources management (NRM1)]; ii) water consumption (NRM2); iii) agrochemicals consumption (NRM3); iv) diesel consumption (NRM4); v) straw availability [rural livelihoods (RLV1)]; vi) contribution to household food security feasibility (RLV2); vii) access to machinery (RLV3); viii) yield stability [comparative advantage (COA1)]; ix) production costs (COA2); $\mathrm{x})$ farm income (COA3); xi) labour demand (COA4).

We then asked participants to weigh the relative importance of each indicator to increase a farm's productivity in the long-term. They had to allocate 100 points amongst the various indicators, where the most important one should receive the highest score. The total score had to add up to 100 . We ran the session with researchers, policy makers, and farmers.

In order to obtain the final scores, we used a simple additive weighting method (Giupponi et al., 2008): we multiplied the weights (0 to $100)$ by the indicators' performance under conventional and CA systems ( 0 to 5 ). This is the only step, where both systems were addressed, the rest of the analysis focuses on CA.

\section{What is the causal relationship between the variables that affect a farmers' decision to convert? (Step 2b)}

We categorised the results of the MCA evaluation into a conceptual map (Step 2b). A conceptual map is a graphical representation of a mental model where concepts are linked to each other through adequate graphical symbols (Giupponi et al., 2008). The map describes the elements and cause-effect links that may affect a farmers' decision to adopt $\mathrm{CA}$. The aim of the discussion, which took place during the same workshop as the MCA phase, was to define a shared scheme to frame the elements determining farmers' decisions. Local farmers and agronomists helped us refine our initial map.

\section{Bayesian network development (Steps 3 to 5)}

Steps 3 to 5 concentrated on the construction of a BDN, coherent with the conceptual map. BDN models are directed acyclic graphs (i.e., without feedback loops) for joint probability distributions, where the nodes represent random variables, and the edges signify direct dependence (Lunn et al., 2000). Each node has 1, 2, or 3 parent nodes. Each node of the BDN represents a system component and has a finite set of mutually exclusive and exhaustive states. The states or conditions of the nodes can be categorical, continuous, or discrete (Carpani and Giupponi, 2010) (Table 1).

Each node is associated to a probability function that takes as input a particular set of values from the node's parent variables.

The Bayes' theorem states that the probability of a hypothesis A is conditioned upon some evidence B (Eq. 1):

$P(A \mid B)=\frac{P(B \mid A) P(A)}{P(B)}$

where the posterior probability of an event $\mathrm{A}, \mathrm{P}(\mathrm{AlB})$, is obtained by multiplying the prior probability of event $\mathrm{A}, \mathrm{P}(\mathrm{A})$, with its likelihood $\mathrm{P}(\mathrm{B} \mid \mathrm{A})$ normalized dividing by $\mathrm{P}(\mathrm{B})$, given that $\mathrm{B}$ is true (Castelletti and Soncini-Sessa, 2007; Carpani and Giupponi, 2010; Catenacci and Giupponi, 2013).

Hence, the BDN model represents the probabilities of relationships between the variables (nodes) of a system. The probabilities that define the connection between nodes are described in conditional probability tables (CPT). We filled each node of the BDN with the conditional probabilities elicited either from available data, or from experts by means of a questionnaire (Table 1 ).

The probability representing our knowledge of the subject before new evidences arrive or policies are tested is called prior. The prior indicates the probability that an input parameter will be in a particular state. When new data or information becomes available, the prior probabilities can be updated. In this specific work, the BDN helped us in assessing: i) the causal impact between the variables that may affect a farmers' decision to convert to CA; and ii) how the introduction of different policy measures targeting certain nodes may affect the adoption rates of $\mathrm{CA}$.

\section{Table 1. Why a Bayesian decision network model?}

We had field data, but mainly from demonstration trials. At the same time, local operators possessed high empirical knowledge. And we wanted to be able to quantify the links between implementing policies and the final rates of adoption, in a way that could maximise the data sources available. In Morocco, the severe data gap on CA compatibility with the existing farming systems makes it difficult to use more traditional data-driven system analysis. A dynamic model allows a temporal analysis and can run at once hundreds of policy scenarios. Yet, we would need to make too many modelling assumptions were we to build either a system dynamic model, or a global equilibrium model, for instance. Instead, BDNs are increasingly being used for natural resources management under uncertainty (Barton et al., 2008). In our study, the two main uncertainties relate to data and farmers' reactions. The main strengths of BDN are their ability to integrate different data sources (e.g., quantitative, semi-quantitative, data-based, opinion-based), to be able to reproduce the system's behaviour even with missing data, and to account for and help communicate uncertainty.

CA, conservation agriculture; BDN, Bayesian decision network. 
The final outcome of our BDN model represents the probability that the adoption node will be in a particular state (i.e., adoption or no adoption), given the available evidence and the conditional probabilities governing how the probabilities combine (Balbi et al., 2014) [In this model, we did not assume a specific statistic distribution between the values in the CPT. We instead introduced in most nodes 3 discrete values of probabilities, which usually should resemble a normal distribution in that the high and low should usually be lower than the central value.]. Despite their remarkable power and high suitability to our problem, there are some inherent liabilities to BDNs, too. The main limitation centres on the quality and extent of the prior beliefs used in the Bayesian inference processing (i.e., the CPTs elicited from experts). A BDN is only as useful as this prior knowledge is reliable. Either an excessively optimistic or pessimistic expectation of the quality of these prior beliefs will distort the entire network and invalidate the results. Related to this concern is the selection of the statistical distribution (already mentioned above) induced in modelling the data. Selecting the proper distribution model to describe the data has a significant effect on the quality of the resulting network. For sake of simplicity, in this exercise we use a discrete or Gaussian distributions.

In Steps 4 and 5, we asked for experts' support in three different phases of the BDN model development: i) two local experts from INRA helped us formalise the conceptual BDN model (Step 3), validate the states of the various nodes (Table 2) and refine the questionnaire for the CPTs' evaluation; ii) eleven experts compiled either the full CPTs or partial subsets through an ad hoc CPT evaluation questionnaire [The questionnaire, in French, is available upon request.]. These were two agronomists involved in agricultural projects in Morocco, six Moroccan agronomists from INRA Settat and INRA Rabat, two Moroccan farmers, and a governmental agency, which supports the World Bank in the implementation of campaigns for the promotion of $\mathrm{CA}$; iii) the same two local experts from INRA validated the behaviour of the model with full CPTs and helped us refine the policy packages to test [Step 4 (last phase)]. The CPTs of each of the experts provide a measure of the uncertainty associated to each of the model's nodes. We carried out an uncertainty analysis by running the model in the baseline once with the values from each experts' response. The probability of yes adoption in the different priors only varied $0.05 \%$ between the responses that led to the maximum and minimum levels of adoption rates. Hence, for the final prior that we kept for policy evaluations (Step 6), we decided to keep the average values of the different experts, for each CPTs in each node of the BDN model (Buntine, 1996; Carpani and Giupponi, 2010).

\section{How do adoption rates vary by removing certain con- straints? (Step 6)}

Once the BDN was completed and the prior validated by experts, we ran several policy scenarios. We prioritised those policies that: i) addressed the constraints emerged during the MCA phase; and ii) the
World Bank identified as priority actions in their latest report on introducing CA in the region (The World Bank, 2014b). According to the World Bank report, the three main constraints for the large scale implementation of CA are: i) crop rotation and weed control; ii) the integration between farming and livestock, for residue retention; and iii) the availability of no tillage seeders (The World Bank, 2014b).

The policy scenarios we simulated were either individual interventions (i.e., on one node), or a combination of policy packages (i.e., acting on several nodes at the same time). We tested against the baseline (i.e., current context, no new policies) the following policies:

- Policies addressing weed control, by either incentivising the appropriate crop rotation (cereals-legumes), or helping with weed control: i) removing state controlled wheat prices, now set by a national law, and allowing them to follow market flows; ii) subsidising legumes' prices; iii) facilitating access to herbicides.

- Policies addressing the integration between farming and livestock, by promoting residue retention: i) increasing availability of residues left on the field, by for instance incentivising the farmer with cash transfer, or by introducing alternatives for animal feed.

- Policies improving the availability of no tillage seeders: i) optimal provision of no tillage seeders: farmers can access a no tillage seeder whenever it is needed, either via cooperatives or by owning them; ii) medium provision of no tillage seeders: the seeders are available a bit later than at the optimal time, due to their scarce number.

- Policies improving access to information: i) optimal access to information via training and demonstration: farmers become well versed in all three pillars of CA and can confidently implement them; ii) medium access to information via training and demonstration: farmers become well versed in one or two of the CA pillars.

We also tested combinations of these policies: i) optimal access to information via training and demonstration and medium access to no tillage seeders; ii) medium access to information via training and demonstration and medium access to no tillage seeders; iii) optimal access to inputs and information; iv) increasing availability of residues and subsidising legumes' prices; v) optimal access to herbicides and subsidising legumes' prices; vi) all policies (improving information, availability of herbicides, access to no tillage seeder; raising legumes' prices, promoting rotation, and incentivising leaving residues on the parcel). Finally, we tested the baseline and the policy, which led to the highest adoption rates under current climate, under two climate scenarios: i) climate slightly drier than today: Ombrothermic index (OI) $>2$ in $60 \%$ of the growing season, and rains arrive either too early, or too late [The $\mathrm{OI}$ is the average monthly precipitations ( $\mathrm{mm}$ ) divided by the average temperature $\left({ }^{\circ} \mathrm{C}\right)$. If $80 \%$ of the growing season has $0 \mathrm{I}>2$, the climate is favourable (Balaghi et al., 2013).]; ii) climate extremely dry: $0 \mathrm{I}>2$ in less than $40 \%$ of the season and rains arrive either too early, or too late.

We ran these policy scenarios for all farmers, and then separately for each typology of farmers (i.e., small, medium, and large).

Table 2. Example of conditional probability tables. This example was one question of the questionnaire submitted to experts.

For each typology of farmers, what is in your opinion the probability that he/she could introduce the rotation cereal-cereal, cereal-legumes (for human consumption), or cereal-forage, considering two scenarios: with or without the introduction of incentives for legumes? The sum of each column needs to be 100.

\begin{tabular}{|c|c|c|c|c|c|c|}
\hline Farm typology & \multicolumn{2}{|c|}{$\begin{array}{l}\text { Smallholders } \\
\text { (<5 ha })\end{array}$} & \multicolumn{2}{|c|}{$\begin{array}{c}\text { Medium farms } \\
(5-20 \mathrm{ha})\end{array}$} & \multicolumn{2}{|c|}{$\begin{array}{l}\text { Large farms } \\
(>20 \mathrm{ha})\end{array}$} \\
\hline Subsidies/incentives for legumes & Yes & No & Yes & No & Yes & No \\
\hline
\end{tabular}

Cereals-cereals

Cereals-legumes (human consumption)

Cereals-forage

$$
=100
$$
$=100$ $=100$ $=100$ $=100$ $=100$ 


\section{Results}

\section{Variables that affect a farm's long term performance (Step 2)}

Via the MCA preference elicitation, we tried to identify the farmers' perceptions on the comparative performance of the two systems (i.e., conventional tillage versus CA). We aggregated the participants' answers via simple additive weighting and ran MCA with the averages for the group and for each individual.

Fifteen participants answered the questionnaire on the MCA: 13 researchers and two farmers. Figure 3 shows the average weights on the participants' views on the relative importance of the variables for farm performance. On average, soil erosion, water consumption, farm income, and yield stability seem to concern participants the most. However, when we looked at the individual weights of the two farmers, soil erosion and water consumption scored much lower. This may indicate a disconnect between researchers' and farmers' perceptions on the long-term advantages of CA. Farmers are more concerned about economic considerations than the environmental advantages of CA. On average, CA scored higher than conventional agriculture (Figure 4). Interestingly however, CA scored lower than conventional agriculture in the two farmers' responses. For both farmers, the main constraints of CA were the consumption of chemical inputs and access to the no tillage seeder, but also food security and farm income. The evidence that these latter two indicators are generally main promoters of CA indicates that better information may help shed clarity on the advantages of CA

The MCA exercise helped identify possible bottlenecks in the adoption of CA. However, due to the lack of quantitative farm data, a solid MCA evaluation could not be pursued. Therefore, for the reasons mentioned above, we combined the information collected in this Step to build a cognitive map of the drivers to adoption and, on this basis, the BDN model. The cognitive map contains a simplified and qualitative version of the nodes of the BDN model.

\section{The Bayesian decision network for the adoption of conservation agriculture in Central Morocco (Steps 3 to 5)}

The first output of the study is a functional BDN model for the adoption of CA in Central Morocco. The resulting BDN model contains physical (i.e., soil and climate), technical (i.e., availability of inputs), and market components (i.e., subsidies and market conditions), in addition to farm management variables (i.e., farm size, rotation, residues availability) (Figure 5). Climate change is important as in the long-term, drier years may occur more frequently and it is proved that no tillage performs better in drier conditions, but not extremely dry [nor wet (Johansen et al., 2012) ]. Hence, we wanted to simulate what may happen to the adoption rates under a different climate.

The results rely on a few experts' elicitations, but from our simulations, it emerges that constraints for the small farmers are much more severe than for medium and large farmers. The adoption rates in the current context that emerged from the model's prior are in line with real rates for both Morocco and other parts of the world: $<1 \%$ of all farmers: $0.1 \%$ of small farmers, $1.2 \%$ of medium farmers, and $2.3 \%$ of large farmers (Giller et al., 2009; The World Bank, 2014b).

\section{Policy analysis (Step 6)}

Once we had a clear prior, we ran the policy scenarios. Perhaps as expected, the highest rate of adoption - around 18\% on average derives from the provision of optimal inputs and information to farmers, without influencing the market or on field farming practices

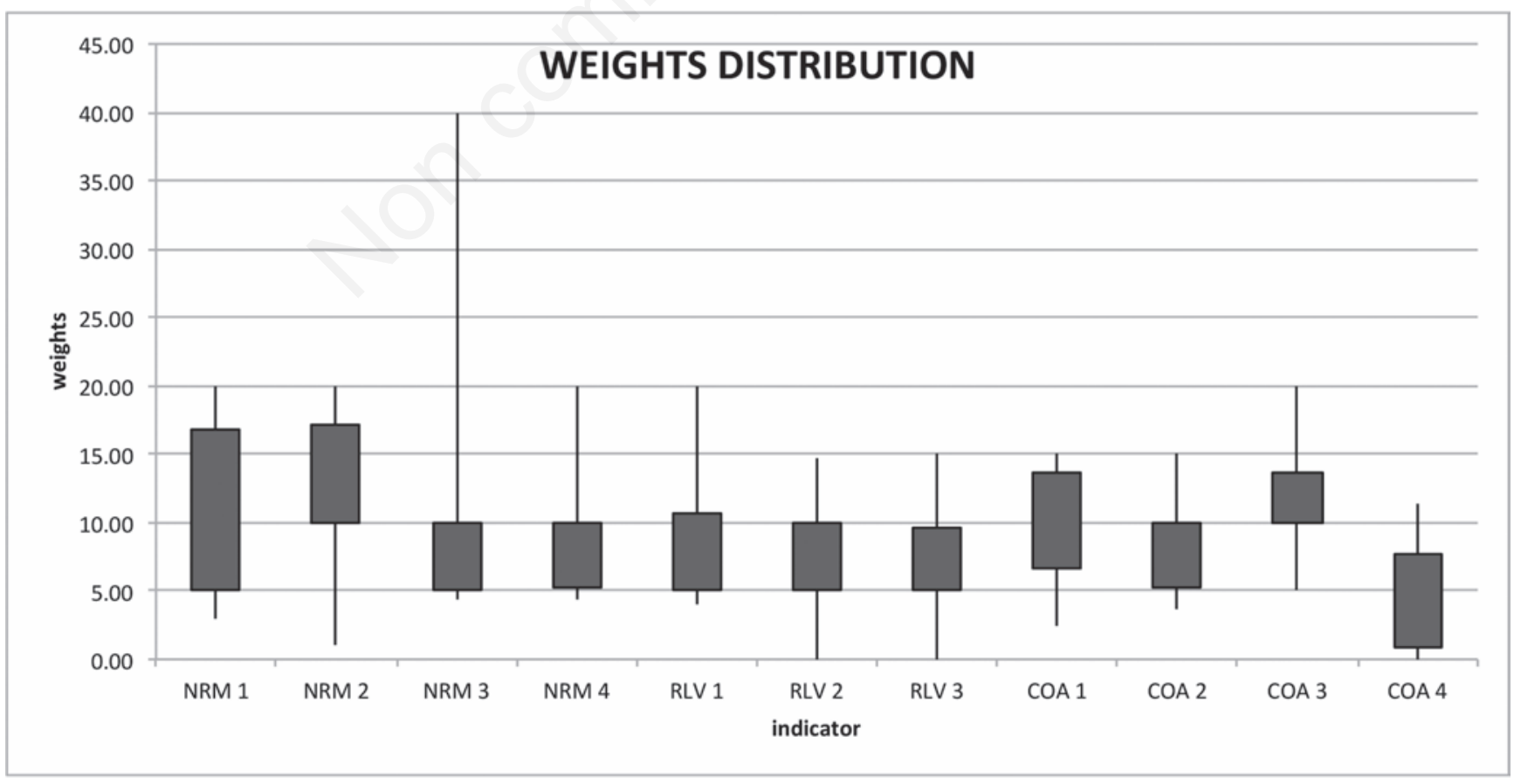

Figure 3. Results of the weights' elicitation. NRM, indicators related to natural resources management; RLV, indicators related to rural livelihoods; COA, comparative advantage. 
(Figure 6). However, this is unlikely to occur in practice in the region. We should bear in mind that the node inputs and information is the results of different states in the availability of the no tillage seeder, herbicides, and information/trainings - to date, it is still unlikely that farmers have optimal access to all three.

An optimal access to the no tillage seeder alone may raise overall rates of adoption to $6 \%$ for medium farmers and to $10 \%$ for large farmers - but only to $2 \%$ for small farmers (Figure 6). Most policy makers and international organisations seem to believe that increasing the availability of no tillage seeders may solve most of the issues related with the adoption of CA, and in turn help achieve food security in the area. The World Bank has recently introduced a system of subsidies for the acquisition of no tillage seeders. Our results scale down the expectation of success of the introduction of subsidies for the no tillage seeders. This is surely an improvement, but it also shows that by itself, the access to a no tillage seeders would not be able to ensure adoption, particularly for small farmers

Information, for instance, may help raise these rates quite significantly, if coupled with the improved availability of no tillage seeders. Indeed - and although the values are preliminary - it seems that the two together may raise overall rates adoption to $11 \%$. This includes an

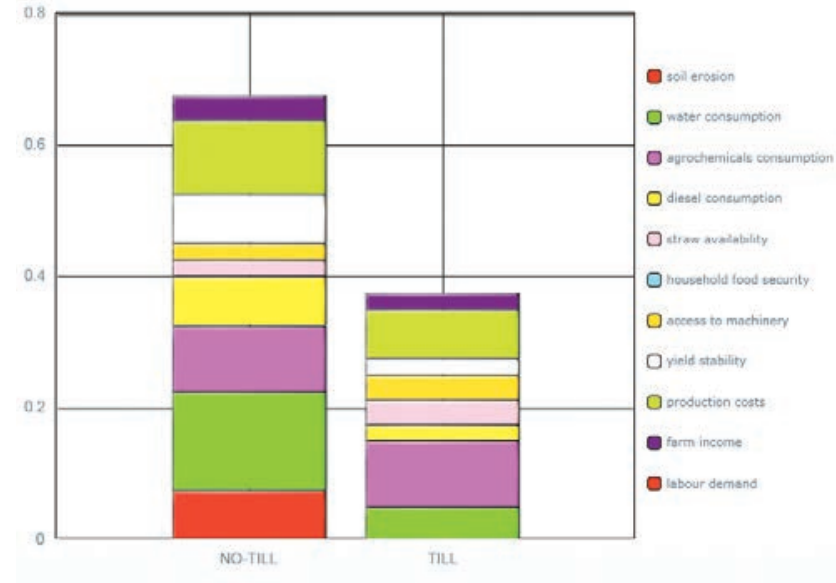

Figure 4. Average performance of conservation agriculture versus conventional tillage systems.

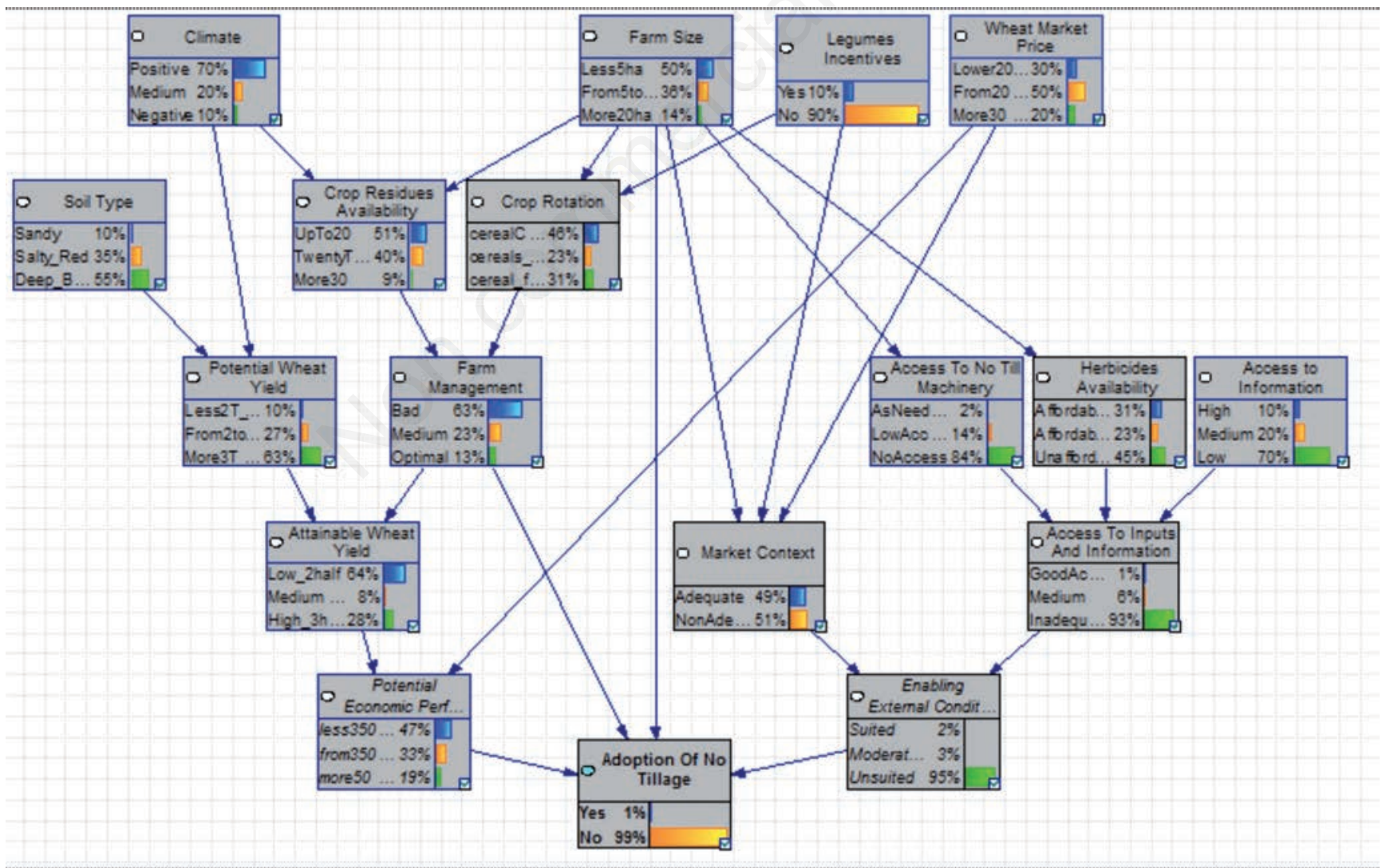

Figure 5. The Bayesian network development model's prior (for the description of the nodes, and their definition, please refer to Table 3. The nodes potential economic performance and enabling external conditions are in italics because their performance is completely endogenous to the model. The output of the model $(\mathrm{P}(\mathrm{A}))$ is the node adoption of no tillage [this model was developed with the Genie software and is available upon request]. 
adoption rate for small farmers of $4 \%$ and of $17 \%$ for larger farmers (Figure 7).

We only ran two climate scenarios (Figure 7). Our preliminary results show that under an extremely dry climate, with everything else remaining constant, adoption rates may decrease even further (down to $0.54 \%$ from $0.9 \%$ for all farmers). These are only a few scenarios that should be taken with care. We would need to run more scenarios to derive significant conclusions on the impact of climate change on adoption rates. However, the model intends to suggest that under extreme climates, for a farmer, adopting CA may be not be worth the risk of transforming its production system. CA may help buffer climate variation in already semi-dry areas to a certain extent, but it is not a panacea for all climate pressures, at least for some farmers. As such, policy-makers should carefully examine the context in which they promote CA and run different scenarios that combine both climate and socio economic conditions (Kassam et al., 2014).

The negative impact of extreme climate on adoption becomes more apparent when we examine the adoption rates under negative climate but when information about CA has improved and farmers have a medium access to the no tillage seeders. Under current climate, this was one of the most effective policy packages, amongst the ones we tested: around $11 \%$ on average, with nearly $18 \%$ of adoption rates for large and medium farmers and $4 \%$ for smallholders. Compared to a non-climatechange scenario, an extremely dry climate reduces the adoption rates of this package by about $40 \%$ for all farmers. However, if we evaluate each farmer typology independently, we notice that the change in adoption due to climate change is much smaller for large farmers (35\%) than for small farmers (54\%).

An interesting result emerges when we simulate the introduction of medium access to the no tillage seeders, optimal information and access to herbicides, more than $30 \%$ residues on the field, a cerea//legumes rotation, and incentives for legumes. In this scenario, the adoption rates - as expected - increase significantly. They are $39 \%$, $40 \%, 39 \%, 37 \%$ respectively for all, small, medium, and large farmers. Interestingly, in this scenario, adoption rates are higher for small farmers. However, in terms of total surface under CA, which is the objective of the Moroccan Government's Plan Vert (The World Bank, 2014a), the rates of adoption of large farmers are much more significant.

\section{Discussion and conclusions}

In this study, we use BDN for the probabilistic assessment of the influence of different policy packages on adoption rates of CA. Our results are based on the expertise of a limited group of experts and numbers should be taken with care. However, this paper offers two contributions to the literature.

Firstly, our analysis suggests that methods like BDN can provide decision makers with important information about the drivers and bottlenecks to adoption of a policy, or, in this case, of a technological package. For a policy question like the promotion of CA in Central Morocco and other parts of the world, the BDN model provides a useful tool for policy exploration and help focus on the right factors: i) the BDN model helps overcome the problem of data gaps by combining different data sources (i.e., empirical data and experts' judgements). BDNs allow a structured formalisation of experts' knowledge via a robust mathematical framework; ii) the CPTs developed upon the variability of opinions of the experts involved allow us to include a notion of uncertainty in the BDN; iii) the BDN model helps decision makers considers the ripple

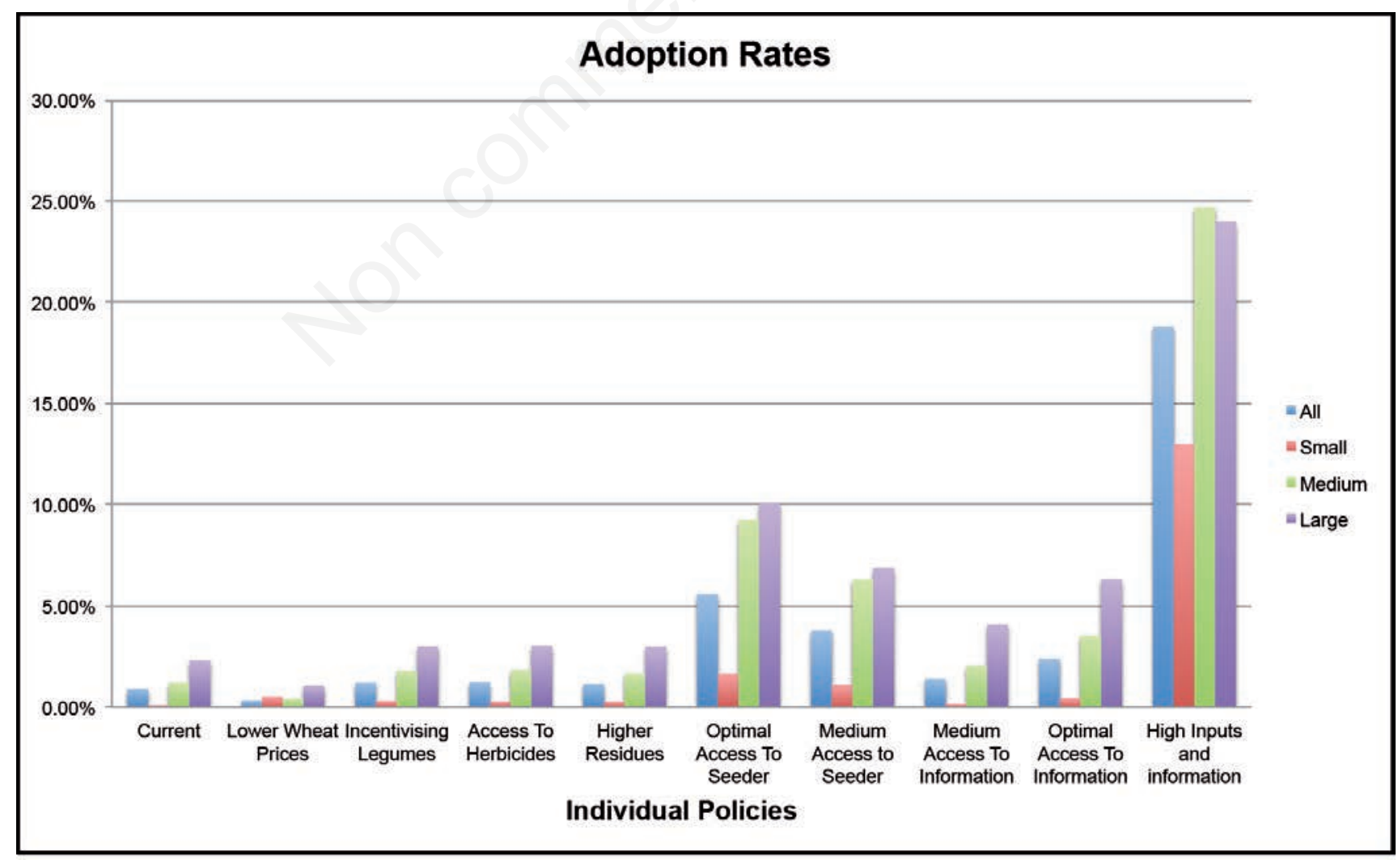

Figure 6. Adoption rates of the individual policies (Step 6). 
effect of various policies. It helps approach adoption from a system's perspective. Indeed, it is important to remember that technical performance at field level is but one of the determinants of adoption (Giller et al., 2011); iv) the BDN model can be updated as new information is collected. This is particularly useful in a policy project that spans across several years, like the diffusion of CA. Indeed, adoption of new technologies is usually achieved through a step-by-step attitude. Hence, BDN can help monitor socio economic changes and their impact on adoption; v) the BDN model is a useful tool to conduct exploratory policy analyses. Most studies to date focus on ex post analysis (Knowler and Bradshaw, 2007). However, as the authors show, there are no clear universally significant factors affecting CA adoption, so we should refrain from developing policies that promote globally CA. Within each context, policy makers should devote efforts to identify the drivers and constraints for adoption and BDN provide a useful mechanism; vi) this specific BDN model is constructed for Central Morocco. However, the same network could be tailored and used in different parts of the world where CA is being introduced.

Table 3. Nodes and ranges of the Bayesian decision network model.

\begin{tabular}{llllll} 
Variables & Units & Source & Low & Medium & High \\
Climate & OI & (Balaghi et al., 2013) & Negative climate & Medium climate & $\begin{array}{c}\text { Positive climate } \\
\text { Combination of monthly } \\
\text { rainfall and average temperature, } \\
30 \text { years of daily data* }\end{array}$ \\
Soil type & $\begin{array}{l}\text { Soil Hydrologic } \\
\text { Groups }\end{array}$ & (USDA, 1986) & A & B & C \\
\hline Potential wheat ton/ha & INRA & $<2$ & 2 to 3 & $>3$
\end{tabular}

yield

\begin{tabular}{|c|c|c|c|c|c|c|}
\hline Farm size & ha & (ACLIMAS, 2013) & $<5$ & 5 to 20 & $>20$ & Percentage of farmers \\
\hline $\begin{array}{l}\text { Crop residues } \\
\text { availability }\end{array}$ & $\%$ & (Mrabet, 2011) & 0 to 20 & 20 to 30 & $>30^{\#}$ & $\begin{array}{l}\text { This node expresses the integration } \\
\text { between livestock and cropping, } \\
\text { very strong in small and medium farms }\end{array}$ \\
\hline Crop rotation & $\%$ & $\begin{array}{l}\text { (ACLIMAS, 2013; } \\
\text { The World Bank, 2014a) }\end{array}$ & $\begin{array}{l}\text { Cereal/cereals } \\
\text { (and others) }\end{array}$ & $\begin{array}{l}\text { Cereals/ } \\
\text { food legumes }\end{array}$ & Cereal/forage & $\begin{array}{l}\text { Percentage of farms } \\
\text { choosing each rotation, on average }\end{array}$ \\
\hline $\begin{array}{l}\text { Farm } \\
\text { management }\end{array}$ & Category & Experts & Bad & Medium & Optimal & $\begin{array}{l}\text { This node aggregates crop rotation and } \\
\text { crop residues availability }\end{array}$ \\
\hline $\begin{array}{l}\text { Attainable } \\
\text { wheat yield }\end{array}$ & ton/ha & $\begin{array}{l}\text { Experts; } \\
\text { (ACLIMAS, 2013) }\end{array}$ & $<2.5$ & 2.5 to 3.5 & $>3.5$ & - \\
\hline $\begin{array}{l}\text { Legumes' } \\
\text { incentives }\end{array}$ & Binary & Experts & No & - & Yes & $\begin{array}{l}\text { These could be introduced either via } \\
\text { prices or other incentives }\end{array}$ \\
\hline $\begin{array}{l}\text { Wheat market } \\
\text { price }\end{array}$ & $\mathrm{DH} / \mathrm{ha}$ & $\begin{array}{l}\text { (Boukantar and } \\
\text { Hanson, 2014) }\end{array}$ & $<2000$ & 2000 to 3000 & $>3000$ & $\begin{array}{l}\text { Currently fixed by the Government at } \\
2500 / 2800\end{array}$ \\
\hline Potential & Composite & (Boughlala and Dahan, & $<3500$ & 3500 to 5000 & $>5000^{\S}$ & - \\
\hline
\end{tabular}

economic indicator 2011)

performance

(wheat)

\begin{tabular}{lllllll}
$\begin{array}{l}\text { Access to } \\
\text { no till seeder }\end{array}$ & Category & $\begin{array}{l}\text { (Boughlala and Dahan, } \\
\text { 2011; The World Bank, 2014a) }\end{array}$ & No access & Low access & As needed & $\begin{array}{l}\text { Low access can either be late access } \\
\text { or sporadic access }\end{array}$ \\
\hline $\begin{array}{l}\text { Access } \\
\text { to information }\end{array}$ & Category & Experts & Low & Medium & High & $\begin{array}{l}\text { Medium information is partial } \\
\text { information on the three pillars of CA }\end{array}$
\end{tabular}

\begin{tabular}{lllllll}
$\begin{array}{l}\text { Herbicides' } \\
\text { availability }\end{array}$ & Category & (The World Bank, 2014b) & $\begin{array}{l}\text { Unaffordable } \\
\text { and available }\end{array}$ & $\begin{array}{l}\text { Affordable } \\
\text { but unavailable }\end{array}$ & $\begin{array}{l}\text { Affordable } \\
\text { and available }\end{array}$ & - \\
\hline $\begin{array}{l}\text { Access to } \\
\text { inputs and } \\
\text { information }\end{array}$ & $\begin{array}{l}\text { Composite } \\
\text { indicator }\end{array}$ & Experts & Inadequate & Medium & Suitable & $\begin{array}{l}\text { Depends on availability of } \\
\text { the machinery, herbicides, } \\
\text { and information }\end{array}$
\end{tabular}

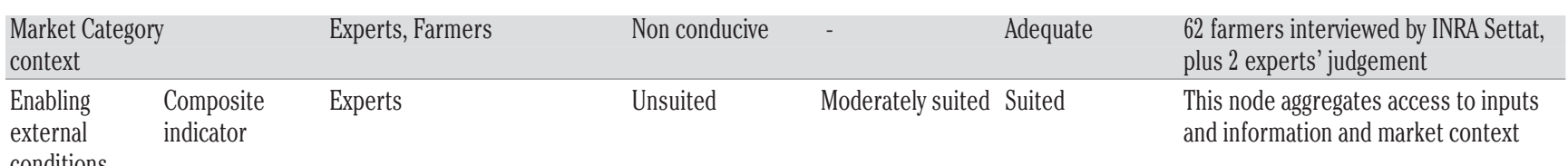

conditions

Adoption of Category Experts No Norcentage of total ha

no tillage

OI, Ombrothermic index; CA, conservation agriculture. *Different percentages of months with $\mathrm{OI}>2$. If $80 \%$ of the growing season has $\mathrm{OI}>2$, the climate is favourable. The climate is medium if the $\mathrm{OI}>2$ in $60 \%$ of the growing season, and rains arrive either too early, or too late; and it is negative, if OI>2 in less than $40 \%$ of the season and rains arrive either too early, or too late; ${ }^{\circ} \mathrm{A}=\mathrm{sand}$, loamy sand, or sandy loam; $\mathrm{B}=\mathrm{silt}^{\mathrm{a}} \mathrm{loam}$ or loam; $\mathrm{C}=$ clay loam, silty clay loam, sandy clay, silty clay, or clay; "INRA suggests that at least $30 \%$ of crop residues is favourable to the adoption of no tillage; ${ }^{\circledR}$ INRA has calculated that the average net profit on a conventional tillage farm is about $4000 \mathrm{DH} / \mathrm{ha}$ for large farmers and $1700 \mathrm{DH} /$ ha for small holders. INRA also estimates that net benefits with no-tillage could potentially be around $6000 \mathrm{DH} / \mathrm{ha}$, regardless of farm size. 
On the other hand, one should use BDN models with care because the results are highly dependent on the prior beliefs. Not only experts' judgements, but also the probability distribution used, can significantly affect the outputs of the analysis. Moreover, the impact of the various nodes on the final outcome varies according to the node's distance from the final decision, so it is crucial to validate the prior with experts.

Secondly, in terms of policy messages and despite being preliminary and based on a small sample of experts and of scenario runs, the outputs of our analysis provide useful information on adoption rates: i) our results show that the target set by the Moroccan Government for the next 10 years is quite ambitious. For instance, in the Central Morocco region, the objective is to extend CA from the current 500 ha to 60,000 ha between now and 2025 (The World Bank, 2014a). This would signify that $90 \%$ of farmers in the area would have to adopt CA when according to the model, the most optimistic combination of policy measures suggests adoption rates of about $40 \%$; ii) there is no one size fits all policy to promote CA. Adoption rates and reaction to the same policy package vary tremendously between different typology of farmers, and within specific pedoclimatic and socio economic conditions. It is therefore crucial to design appropriate policy packages for each specific typology of farmers, within their own contexts; iii) in particular, if the objective of introducing CA is to improve food security in the Central Morocco area, decision makers should pay particular care to smallholders' limiting conditions to the adoption - besides their generally higher vulnerability to external drivers than large farmers.
In this regard, we show that the diffusion of information about the long and short-term benefits of CA is crucial. This is in line with existing literature. For instance, smallholders are typically concerned with meeting their more immediate needs and are therefore easily deterred from adopting technologies that entail no benefits also in the short term (Baudron et al., 2012).

An interesting next step would be the assessment of the economic feasibility of the various policy packages that we test in this paper. If we had this data, our results could then be integrated with an evaluation of the tradeoffs, for a cost-effectiveness ranking of the actions that may increase adoption rates.

Again, these results are exploratory and do not intend to suggest specific policy actions. Nevertheless, this study shows that in order to promote adoption, policy makers need to identify the critical conditions, the bottlenecks, and their causal links. Only then, they can design successful solutions. It is important to consider the thresholds, the tipping points, and the synergic combination of the variables. Even with manageable challenges to introduce the three pillars of CA, for some farmers it may remain difficult to adopt. If one considers Rogers's five characteristics (Rogers, 2003), policy makers should not neglect compatibility. Indeed, this may threaten the success of the whole process of innovation diffusion. The BDN model described in this paper provides an effective and updatable tool for the integration of compatibility (and complexity, via information) into ex ante policy evaluations, with clear information on the associated uncertainties.

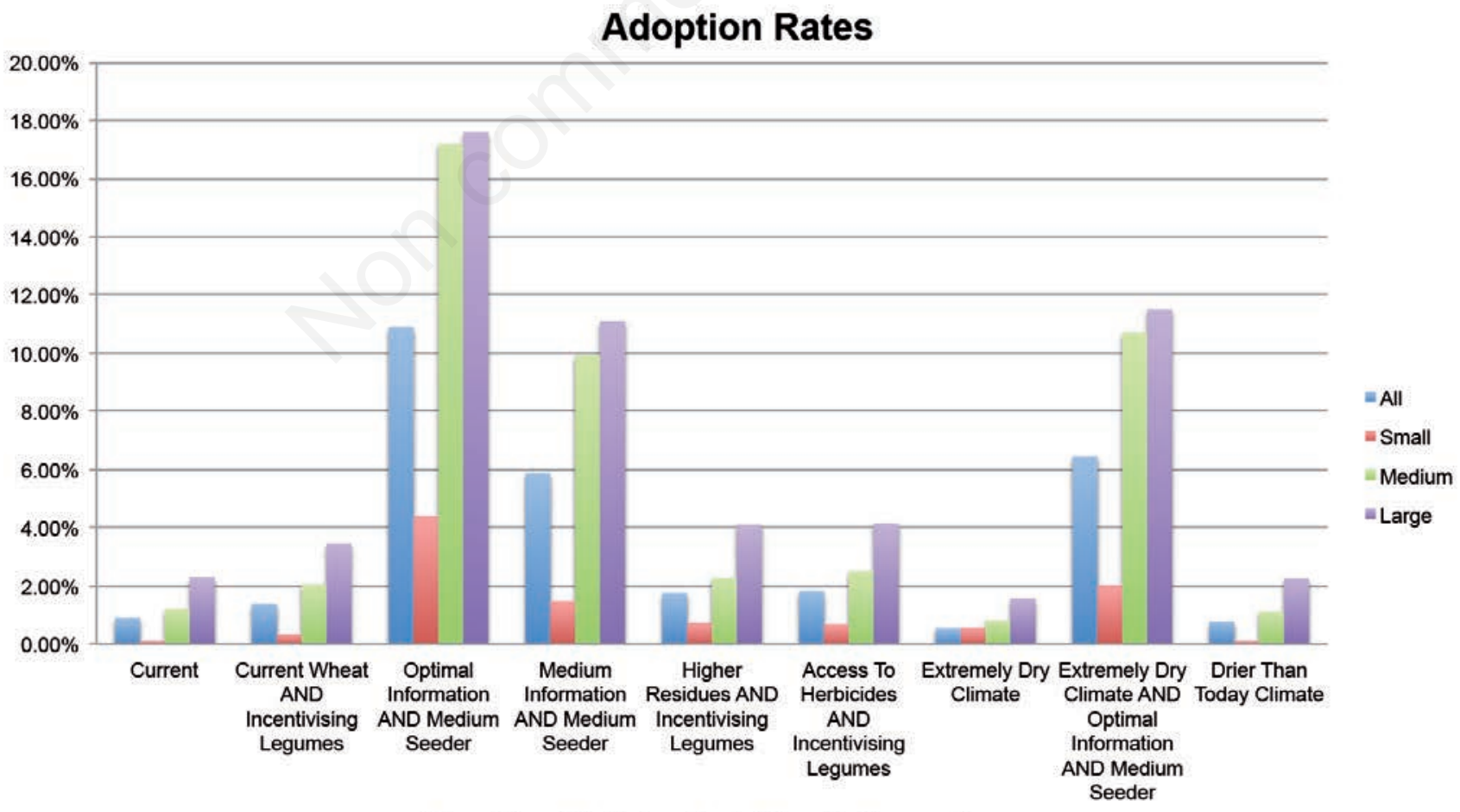

Combined Policies And Climate Scenarios

Figure 7. Adoption rates of combined policies and under climate scenarios policies (Step 6). 


\section{References}

Acevedo E, Martinez E, Silva P, 2014. Constraints to zero tillage in Mediterranean environments. pp 195-206 in Proc. of the 4th World Congress on Conservation Agriculture, New Delhi, India.

ACLIMAS, 2013. Characterisation report of the Chaouia Ouardigha Region, Morocco. INRA-CMCC, Settat, Morocco.

Arrue JL, Cantero-Martínez C, 2006. Third Mediterranean meeting on no tillage. CIHEAM, Bari, Italy.

Balaghi R, Jlibene M, Tychon B, Eerens H, 2013. Agrometeorological cereal yield forecasting in Morocco. National Institute for Agronomic Research, Rabat, Morocco.

Balbi S, Villa F, Mojtahed V, Giupponi C, 2014. Estimating the benefits of early warning systems in reducing urban flood risk to people: a spatially explicit Bayesian model. Social Science Research Network, Rochester, NY, USA.

Barton DN, Saloranta T, Moe SJ, Eggestad HO, Kuikka S, 2008. Bayesian belief networks as a meta-modelling tool in integrated river basin management - Pros and cons in evaluating nutrient abatement decisions under uncertainty in a Norwegian river basin. Ecol. Econ. 66:91-104.

Baudron F, Tittonell P, Corbeels M, Letourmy P, Giller KE, 2012. Comparative performance of conservation agriculture and current smallholder farming practices in semi-arid Zimbabwe. Field Crops Res. 132:117-28.

Boughlala M, Dahan R, 2011. An economic comparison between Conventional and no-tillage farming systems in Morocco. INRA, Settat, Morocco.

Boukantar K, Hanson S, 2014. Morocco - Grain and feed annual (No. M01403), Global Agricultural Information Network. USDA Foreign Agricultural Service, Washington, DC, USA.

Buntine W, 1996. A guide to the literature on learning probabilistic networks from data. IEEE Trans. Knowl. Data Eng. 8:195-210.

Carpani M, Giupponi C, 2010. Construction of a Bayesian network for the assessment of agri-environmental measures - the case study of the Venice Lagoon watershed. Ital. J. Agron. 5:265-74.

Catenacci M, Giupponi C, 2013. Integrated assessment of sea-level rise adaptation strategies using a Bayesian decision network approach. Environ. Model. Software 44:87-100.

Castelletti A, Soncini-Sessa R, 2007. Bayesian Networks and participatory modelling in water resource management. Environ. Model. Software 22:1075-88.

Derpsch R, Friedrich T, Kassam A, Hongwen L, Consultant F, 2010. Current status of adoption of no-till farming in the world and some of its main benefits. Int. J. Agric. Biol. Engine. 3:1-25.

Derpsch R, 2003. Conservation tillage, no tillage, and related technologies. In: L. Luis García-Torres, J. Benites, A. Martínez-Vilela, A. Holgado-Cabrera (Eds.), Conservation agriculture: environment, farmers experiences, innovations, socio-economy, policy. Springer Science \& Business Media.

Dumanski J, Peiretti R, Benetis J, McGarry D, Pleri C, 2006. The paradigm of conservation tillage. pp 58-64 in Proc. World Assoc. Soil and Water Conserv.

Giller KE, Corbeels M, Nyamangara J, Triomphe B, Affholder F, Scopel E, Tittonell P, 2011. A research agenda to explore the role of conservation agriculture in African smallholder farming systems. Field Crops Res. 124:468-72.

Giller KE, Witter E, Corbeels M, Tittonell P, 2009. Conservation agriculture and smallholder farming in Africa: the heretics' view. Field Crops Res. 114:23-34.

Giupponi C, Fassio A, Sgobbi A, 2008. Evaluation of agri-environmental measures in the Venice Lagoon watershed. Expert knowledge elic- itation and multi-criteria analysis. Ital. J. Agron. 3:147-66.

Gonzalez-Sanchez EJ, Veroz-Gonzalez 0, Blanco-Roldan GL, MarquezGarcia F, Carbonell-Bojollo R, 2015. A renewed view of conservation agriculture and its evolution over the last decade in Spain. Soil Tillage Res. 146:204-12.

Haggblade S, Tembo G, 2003. Conservation farming in Zambia. International Food Policy Research Institute, Washington, DC, USA.

Johansen C, Haque ME, Bell RW, Thierfelder C, Esdaile RJ, 2012. Conservation agriculture for small holder rainfed farming: opportunities and constraints of new mechanized seeding systems. Field Crops Res. Conserv. Agric. Dry Areas 132:18-32.

Kassam A, Friedrich T, Shaxson F, Bartz H, Mello I, Kienzle J, Pretty J, 2014. The spread of Conservation Agriculture: policy and institutional support for adoption and uptake. Field Actions Sci. Rep. J. 7:3720.

Knowler D, Bradshaw B, 2007. Farmers' adoption of conservation agriculture: a review and synthesis of recent research. Food Policy $32: 25-48$.

Lahmar R, 2010. Adoption of conservation agriculture in Europe. Land Use Policy 27:4-10.

Lunn D, Thomas J, Best A, Spiegelhalter N, 2000. A Bayesian modelling framework: Concepts, structure, and extensibility. Stat. Comput. 10:325-37.

Moussadek R, Mrabet R, Dahan R, Zouahri A, El Mourid M, Ranst EV, 2014. Tillage system affects soil organic carbon storage and quality in Central Morocco. Appl. Environ. Soil Sci. 2014:e654796.

Moussadek R, Mrabet R, Zante P, Marie Lamachère J, Pépin Y, Le Bissonnais Y, Ye L, Verdoodt A, Van Ranst E, 2011. Effets du travail du sol et de la gestion des résidus sur les propriétés du sol et sur l'érosion hydrique d'un Vertisol Méditerranéen. Can. J. Soil Sci. 91:627-35.

Mrabet R, 2008. No-tillage Systems for sustainable dryland agriculture in Morocco. National Institute for Agricultural Research, Settat, Morocco.

Mrabet R, Moussadek R, Fadlaoui A, van Ranst E, 2012. Conservation agriculture in dry areas of Morocco. Field Crops Res. 132:84-94.

Pittelkow CM, Liang X, Linquist BA, van Groenigen KJ, Lee J, Lundy ME, van Gestel N, Six J, Venterea RT, van Kessel C, 2015. Productivity limits and potentials of the principles of conservation agriculture. Nature 517:365-8.

Rogers EM, 2003. Diffusion of innovations. Free Press, New York, NY, USA.

The World Bank, 2014a. Réalisation de l'étude sur le semis direct dans le cadre du projet d'intégration du changement climatique dans la mise en ouevre du plan Maroc Vert (PICCPMV). Phase 1: Diagnostic analytique de la situation actuelle du systeme de semis direct (SSD) (Document $\mathrm{n}^{\circ}$ : 11706-N711-13a). The World Bank, Washington, DC, USA.

The World Bank, 2014b. Réalisation de l'étude sur le semis direct dans le cadre du projet d'intégration du changement climatique dans la mise en ouevre du plan Maroc Vert (PICCPMV). Phase 2 : Feuille de route pour le developpement et promotion du semis direct au niveau des exploitations agricoles (Document $\mathrm{n}^{\circ}$ : 943-N711-14b). The World Bank, Washington, DC, USA.

USDA, 1986. Urban hydrology for small watersheds (No. Technical Release 55). United States Department of Agriculture, Washington, DC, USA.

Wall PC, 2007. Tailoring conservation agriculture to the needs of small farmers in developing countries. J. Crop Improv. 19:137-55.

Watts D, El Mourid M, 1988. Rainfall patterns and probabilities in the semi-arid cereal production region of Morocco. National Institute for Agricultural Research, Settat Morocco. 